\title{
Spatio-temporal Patterns and Driving Forces of Urban Land Expansion in China during the Economic Reform Era
}

\begin{abstract}
Along with its economic reform, China has experienced a rapid urbanization. This study mapped urban land expansion in China using high-resolution Landsat Thematic Mapper and Enhanced Thematic Mapper data of 1989/ 1990, 1995/1996 and 1999/2000 and analyzed its expansion modes and the driving forces underlying this process during 1990-2000. Our results show that China's urban land increased by 817 thousand hectares, of which $80.8 \%$ occurred during $1990-1995$ and $19.2 \%$ during 1995-2000. It was also found that China's urban expansion had high spatial and temporal differences, such as four expansion modes, concentric, leapfrog, linear and multi-nuclei, and their combinations coexisted and expanded urban land area in the second $5 \mathrm{y}$ was much less than that of the first $5 \mathrm{y}$. Case studies of the 13 mega cities showed that urban expansion had been largely driven by demographic change, economic growth, and changes in land use policies and regulations.
\end{abstract}

\section{INTRODUCTION}

Urbanization is a transformation process from a traditional agricultural society to a modern metropolitan society, associated with major changes in social and economic structures (1-10). As an important component of land use and land cover change, its significance will undoubtedly continue to increase as the majority of the world's population are swarming into cities $(7,11)$.

Unlike the more commonly known Metropolitan Statistical Area $(6,12)$, the urban land in this paper refers to the fully developed area of a central city and its suburbs that includes no rural land. According to such a definition, it is easy to measure the amount of overall expansion based on the monitoring of the Landsat Thematic Mapper (TM) and Landsat Enhanced TM (ETM) digital images. It is also possible to measure the expansion from a certain period to another one by noting the change in overall acreage of a specific urbanized area (hereafter, the urban land for simplicity).

As one of the main indicators to identify the intensity of urbanization, urban land expansion is the most easily identifiable characteristic of the process in the spatial dimension $(12,13)$, because it affects land cover and use at regional and even global scales. Although variety of definitions are given to urban land expansion $(2,6-8,14-16)$, most of them have in common that urban land expansion is the spreading out of a city and its suburbs toward more and more non-built-up areas at the periphery of an urban area $(2,6-8,14-16)$. This process involves the conversion of open space (other land use categories) into built-up developed land over time. For those who are most concerned about the effect of urban land expansion on the natural environment and agricultural resources, the more important overall measure of urban land expansion is the actual amount of land that has been urbanized.

Morphologically speaking, urban land expansion falls into categories, such as concentric expansion, leapfrog expansion, linear expansion, and multi-nuclei expansion or their hybrid. The expansion of a city in all directions that results in large-scale urban sprawl and changes in urban land use is identified as concentric expansion. Urban land expansion showing a scattering of new development on isolated tracts separated from other areas by vacant land (7) is defined as the leapfrog expansion (17), which is typical of many major cities across the world. This kind of expansion is clearly observed on the urban fringes or city peripheral rural areas rather than in the city center. Some urban expansion is defined as linear expansion because it usually occurs along the main transportation axis (e.g. highway, expressway, river), linking the urban areas in a long narrow strip $(1,14,18)$. Finally, a city may have more than one nuclei/center apart from the central business district (CBD); this kind of development is called multinuclei expansion $(1,14,18)$. In this expansion, the cities act as the nodes of activity at the junction of major crossroads in the outer parts of urban areas.

It is widely recognized that demography and economies are the most important driving factors for urban expansion $(8,11,12,19$, 20). Social and economic behavior dominates the processes of urban growth (21). As a result of human activity, the growth of cities is strongly influenced by economic, geophysical, and institutional constraints. Over the last two decades, the rapid urbanization process caused an unprecedented scale and rate of urban expansion in China (19). It is expected that the urban land in China will continue to expand at a very rapid rate, as more than $50 \%$ of the population will be in urban areas by 2030 according to a United Nations projection (21).

The urban land expansion has produced tremendous social, economic, and environmental consequences, including reductions in arable lands, population migration, and polarization of economic growth between cities and countryside $(5,13)$. Urbanization is perhaps one of the most important human activities that creates enormous impacts on the environment at the local and global scales $(6,14)$. Because of the absence of appropriate land use planning and little efforts to promote sustainable development, rampant urban growth and massive loss of agricultural land have posed severe threats (22). The spatial pattern of land use reflects underlying human activity processes and influences the ecology of the urban environment $(2,20)$. With the anticipated rapid economic growth in the future, China's urban land expansion will accelerate. Therefore, it is paramount to understand the spatio-temporal patterns and driving forces of the urban land expansion, which may play an important role in developing rational economic, social, and environmental policies.

This paper presents the scale and characteristics of urban expansion in China during 1990-2000 using remote sensing data and GIS technologies. Then, it identifies the patterns of urban land expansion and the underlying drivers by case studies of 13 mega cities. Our work clearly shows that, based on spatially contiguous and time-specific earth observations at high resolution, satellite remote sensing provides large data archives to measure and analyze spatio-temporal variations in urban lands. Similarly, Geogrphical Information System (GIS) technologies offer a flexible environment for storing, processing, and displaying remote sensing. Remote sensing and GIS application constitute a powerful and effective tool to detect land use and land cover changes $(16,20,23-28)$. However, to fully understand the process of urbanization, it is equally important to look into the social, economic, and institutional backdrop against which 
the land use changes have taken place. Therefore, we also discuss the driving forces and mechanisms of urban expansion as well.

\section{MATERIALS AND METHODS}

The primary data source of this study is the Landsat TM and Landsat ETM images taken in 1989/1990, 1995/1996,and 1999/ 2000 (henceforth, referred to as 1990, 1995, and 2000 data for simplification purposes). The data from bands 2,4 , and 5 , sensitive to land cover changes, were used $(5,29,30)$. In addition, the data from China-Brazil Earth Resource Satellite 1 (CBERS-1) in 2000 were used to mosaic the missing data for some regions. The maximal spatial resolution of the data we used is $30 \mathrm{~m}$. The Landsat images were enhanced using the linear contrast stretching and histogram equalization to help identify ground control points in the rectification to a common ALBERS coordinate system based on 1:100 000 topographic maps of China $(29,30)$.

In view of the inconsistency among the data band's parameters, postclassification comparison and multidate composite image change detection methodology (31) were used to detect and analyze the urban land changes. Meanwhile, an efficient land cover classification system was designed and applied in the study. The land cover classification was conducted through visual interpretation to guarantee the consistency and accuracy of data processing. After geometric correction and georeference, the average location errors in the Landsat images are less than $50 \mathrm{~m}$ (about 2 pixels). Field survey and random sample check show that the overall interpretation accuracy for land use classification (5) is $92.92 \%$ for $1990,98.40 \%$ for 1995 , and $97.45 \%$ for 2000 , and the interpretation for urban land has a higher accuracy rate than that of others (Table 1).

Based on the 1-km GRID global dataset, International Geosphere-Biosphere Programme (IGBP), International Human Dimensions Programme on Global Environmental Change (IHDP), and other international research organizations have conducted a series of research projects to study land cover dynamics and mechanisms using global and regional models (32). The framework of the 1-km GRID dataset organized with an efficient and effective data fusion method was also used in this study. To create the $1-\mathrm{km}$ GRID land-use dataset, we first obtained land use maps of 1990, 1995, and 2000 at a scale of 1 : 100000 and land-use change maps during the periods 1990-1995 and 1995-2000 based on the Landsat TM images and generated vector data at the grid scale of $1 \times 1 \mathrm{~km}$ georeferenced to the China boundary at a scale of $1: 10000$. We intersected the land-use changes maps with the vector data at the grid scale of $1 \times 1 \mathrm{~km}$. Next, we summarized the change areas of each land use category based on cell identification of the vector data at the grid scale of $1 \times$ $1 \mathrm{~km}$. Finally, we converted the vector data into (GRID) raster data using information about the area percentage of land-use change types, in which the urban land expansion data was generated and represented across China (Fig. 1) $(5,29,30)$.

We identified the modes of urban land expansion using the visual analyses based on the interpreted Landsat TM/ETM digital images; it is a more convenient and effective method. In the GIS software environment (here, we used the ArcGIS software), inputting the interpreted urban land data and some other ancillary data (e.g. transportation line, terrain categories), displaying, and comparing the expansion extent, we identified the expansion modes of different cities and got the expanded urban land areas during the first and second $5 \mathrm{y}$.

\section{RESULTS OF AGGREGATE ANALYSIS}

Our study shows that urban land of China increased by 817000 ha during 1990-2000, of which 80.8\% occurred during 1990-1995, and the remaining $19.2 \%$ occurred during 1995-2000. Whereas the expansion speed of the first $5 \mathrm{y}$ was much higher than that of the second $5 \mathrm{y}$, four kinds of urban land expansion modes were found both in the first and second $5 \mathrm{y}$.

Urban land in China increased about 660000 ha or $23.9 \%$ during 1990-1995. As shown in Figure 1, the provinces in central and eastern China with high economic growth and population density, especially those in the coastal area, experienced the most rapid urban expansion $(18,20)$. During 1995-2000, cultivated land protection policies slowed down the real estate development and thus the loss of cultivated land in many regions. However, the implementation of the Western Development Policy revitalized urban land expansion in the west (33). Consequently, cultivated land, forestry area, grassland, water area, and unused land were still converted.

Table 2 indicates that most of the urban expansion came from cultivated land. During 1990-1995, 527000 ha of cultivated land was transformed into urban land, whereas the cultivated land loss reached 129000 ha because of the conversion to urban land during 1995-2000. As can be seen in Figure 1, during 1990-1995, concentric, rapid urban expansion occurred mainly in the BeijingTianjin-Tangshan region, the Yangtze River Delta, the Pearl River Delta, and the southeastern coastal regions. The urban land in the Beijing-Tianjin-Tangshan region rose about $55.3 \%$, accounting for $8 \%$ of the national total urban expansion over the same period.

Located in a well-developed coastal area, the Yangtze River Delta also enjoyed rapid economic growth, and its urban space increased by $24.3 \%$, largely through concentric expansion during 1990-1995. Meanwhile, in the Pearl River Delta, adjacent to Hong Kong and Macao, the economic growth, driven by foreign investments and export, led to rapid urbanization through linear, concentric, or leapfrog expansion. Designated as the largest Special Economic Zone in 1988, Hainan relaxed land use regulation and thus had rapid urban growth induced by the real estate boom. Our study showed that Hainan province had the fastest growth of urban land-more than 60000 ha during 19901995, resulting from the rapid urban land expansion through the concentric or leapfrog modes.

During 1995-2000, the urban growth slowed down to an average rate of only $3.8 \%$ over the $5 \mathrm{y}$, especially in the Pearl River Delta and the Yangtze River Delta. However, significant expansion occurred in the Sichuan Basin and Hanzhong Basin through linear expansions, in the Tibetan Plateau through leapfrog expansion, and in the Yunnan-Guizhou Plateau through linear expansion. The urban land increase in these areas accounted for more than $26 \%$ of the country's total urban land growth.

Specifically, a growth rate ranging from $3.9 \%$ to $6 \%$ was achieved in the Ningxia plain, the Loess Plateau, the

Table 1. Summary of the accuracy validation by each landscape.

\begin{tabular}{|c|c|c|c|c|c|c|}
\hline Items & Cultivated land & Forestry area & Grassland & Built-up area & Other use types & Total \\
\hline SPN1990 (patches) & 5058 & 4104 & 1512 & 1714 & 912 & 13300 \\
\hline AR1990 (\%) & 94.94 & 90.13 & 88.16 & 96.32 & 95.72 & 92.92 \\
\hline SPN1995 (patches) & 20211 & 7585 & 5457 & 1607 & 4366 & 39226 \\
\hline SPN2000 (patches) & 22710 & 7985 & 6656 & 2115 & 4798 & 44264 \\
\hline AR2000 (\%) & 97.33 & 97.42 & 97.43 & 99.15 & 97.31 & 97.45 \\
\hline
\end{tabular}

Built-up area is reclassified into three subcategories: urban land, rural settlement, and industrial and mining areas; the second, fourth, and sixth rows correspond to the sampled patches' numbers for 1990, 1995, and 2000 (abbreviated to SPN1990, SPN1995, and SPN2000, respectively, in the first column), whereas the third, fifth, and seventh rows are the accuracy rates for the 3 y (abbreviated to AR1990, AR1995, and AR2000, respectively). 

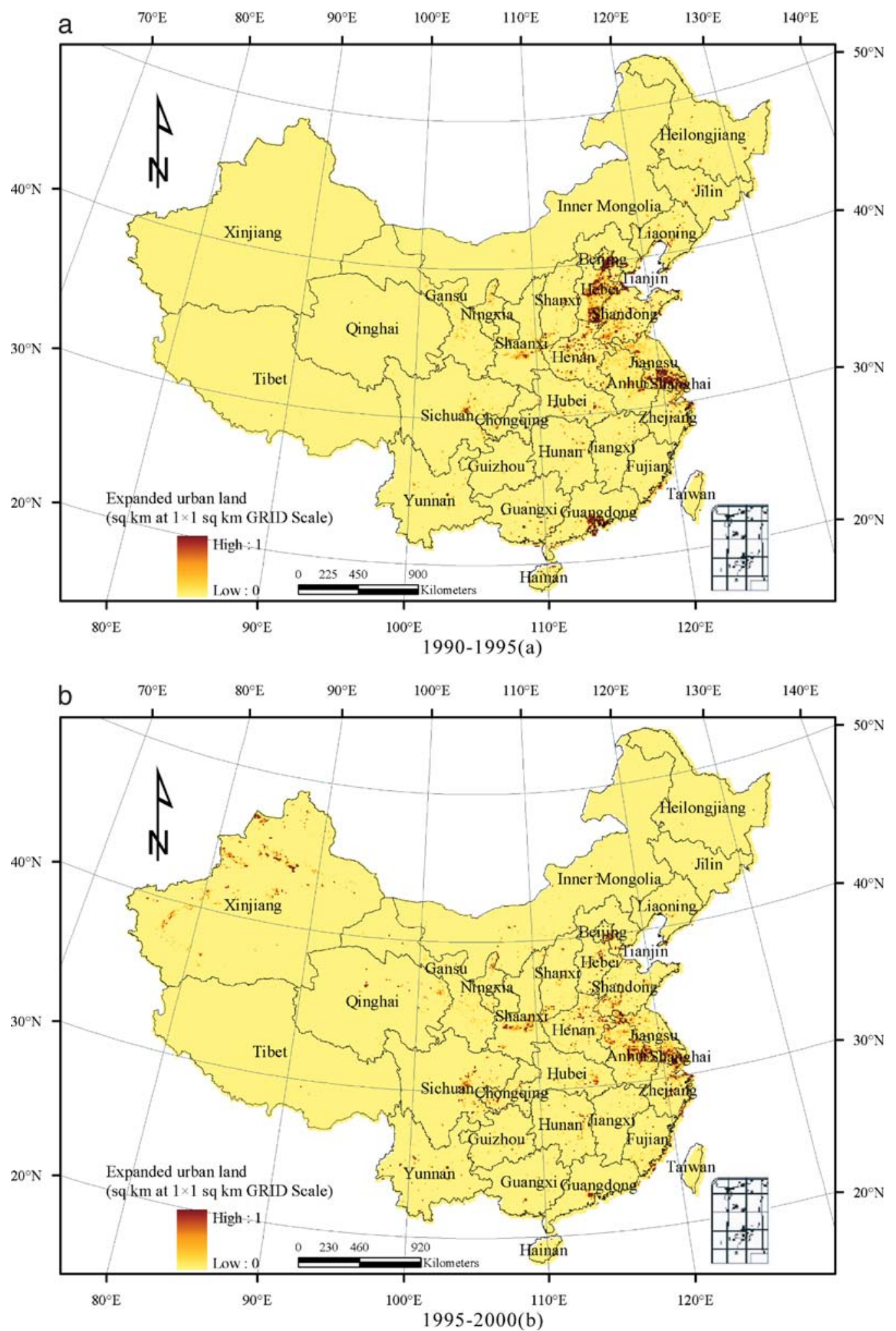

Figure 1. Spatio-temporal differences of urban land expansion during 1990-1995 (a) and 1995-2000 (b).

southeastern coastal areas, the southwest city corridor, and the central Liaoning city corridor. The growth rate of urban lands in the following regions ranged from $1 \%$ to $3.1 \%$ : the central Henan city corridor, the northern China city corridor, the FuzhouXiamen coastal zone, the central Hunan city corridor, the Wuhan metropolis, the central China city corridor, the Taiyuan basin, the Shandong Peninsula, the eastern parts of northeast China, and parts of Inner Mongolia.

\section{CASE STUDIES}

By the end of 2000, there were 13 mega cities in China with more than 2 million in nonagricultural population (34), i.e. Beijing,
Shanghai, Guangzhou, Haerbin, Dalian, Wuhan, Chongqing, Xi'an, Chengdu, Changchun, Tianjin, Nanjing, and Shenyang, among which, 10 cities lie in the eastern part and the others lie in the central part of China. Since economic reform began in 1978, these mega cities have played a leading role in socio-economic development at a regional scale. Identifying the spatial patterns of urban growth is of significance to understand the driving forces of urban land expansion. For this purpose, we selected 13 mega cities to examine the urban land expansion and find the main determinants underlying this process. We believe that our study are valuable for decision-making in land-use planning and management by local and central governments $(5,30)$. 
Table 2. Converted areas from nonurban land to urban land in China during 1990-1995, 1995-2000, and 1990-2000 (in thousand hectares).

\begin{tabular}{ccccccc}
$\begin{array}{c}\text { Time } \\
\text { series }\end{array}$ & $\begin{array}{c}\text { Cultivated Forestry } \\
\text { land }\end{array}$ & area & Grassland & $\begin{array}{c}\text { Water } \\
\text { area }\end{array}$ & $\begin{array}{c}\text { Rural } \\
\text { settlement }\end{array}$ & $\begin{array}{c}\text { Unused } \\
\text { land }\end{array}$ \\
\hline $1990-1995$ & 527 & 32 & 11 & 9 & 93 & 1 \\
$1995-2000$ & 129 & 6 & 10 & 3 & 4 & 4 \\
$1990-2000$ & 656 & 38 & 21 & 12 & 97 & 5
\end{tabular}

Our study of 13 mega cities indicates that the urban land of all 13 mega cities increased nearly 106000 ha, with an annual rate of more than 3.5\%. The urban land of Beijing, Shanghai, and Guangzhou expanded more than 10000 ha, respectively, accounting for $61.5 \%$ of the total expanded urban land areas of all the 13 mega cities. Dalian, Chengdu, Nanjing, and Tianjin have also seen their urban land expand over 5000 ha. The other cities, with relatively low expansion rates, also experienced an urban land increase by the area of 1000-3000 ha. From the perspective of land conversion, $75.3 \%$ of the newly expanded urban land in the 13 mega cities came from cultivated land, whereas $13.9 \%$ and $4.6 \%$ of newly expanded areas were from rural settlement and forestry areas, respectively.

Four kinds of urban land expansion modes could be found in the 13 mega cities in China in 1990-2000. The urban land of Beijing and Chengdu expanded evenly in all directions in the shape of concentric expansion. The Landsat TM/ETM digital images of two periods clearly showed the spatial pattern of the urban land expansion (Fig. 2). However, in Guangzhou and Chongqing, cities that are sprawling along rivers or lakes and are subject to terrain conditions and historical trends of expansion, the urban land expanded mainly along the river or lake in a linear expansion. In Shanghai, Tianjin, and Xi'an, urban expansion was found largely at the periphery of old urban areas or satellite towns in the leapfrog expansion mode. Figure 3 clearly shows the urban land expansion through leapfrog expansion. As mentioned above, a city may expand in a combined mode, e.g. the newly formed urban land of Dalian concentrated mainly in old urban areas, expanded in the mode of concentric expansion, whereas at the northeastern bank of Dalian Bay, urban land increased substantially through linear expansion. Located in northeastern plain of China, Shenyang, Haerbin, and Changchun showed similar patterns of urban expansion, with most of their relatively slight expansion continuously extending along the fringes of old built-up areas; the predominant direction of urban expansion varied among them because of their different infrastructure conditions and the general urban development planning. Constrained by their respective terrain conditions and city general planning $(1,18,30)$, Wuhan and Nanjing showed multinuclei urban land expansion. In a nutshell, varied geophysical con-

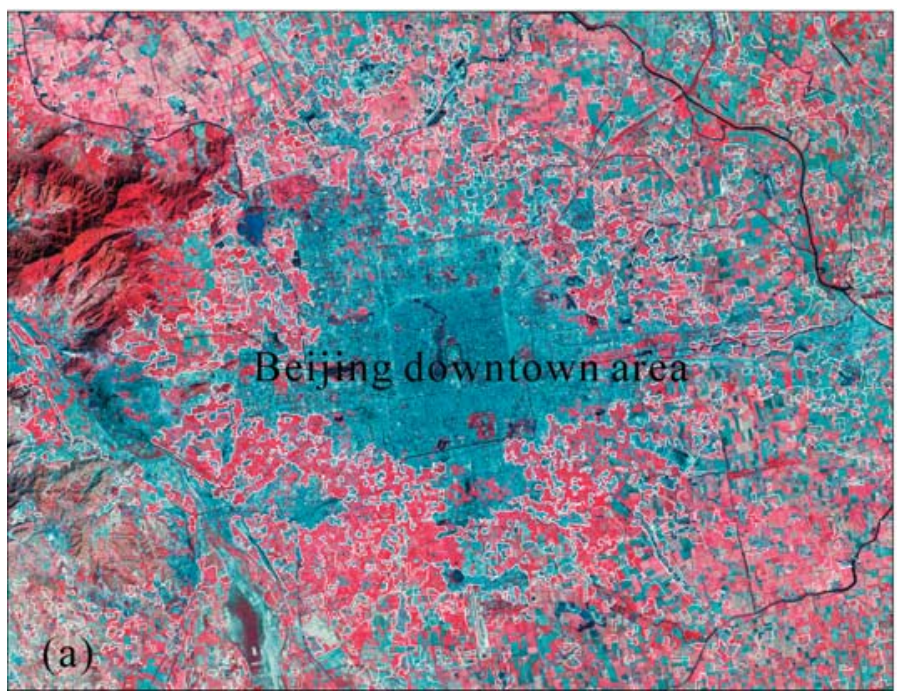

ditions and different socio-economic development levels caused the 13 mega cities to take different expansion modes in 1990 2000 , even under the same policy settings.

\section{DRIVING FORCES}

Recently, many papers have examined the characteristics of urban land expansion at different scales $(15,20,35)$, but relatively less attention has been paid to the driving mechanism of urban land expansion in China $(1,8,20,35)$. China is undergoing the transition from a planned economy to a market economy. Many policies, even newly developed, still bear the mark of the planned economy $(6,8,10,16,35,36)$. The policy changes in land protection or urban development have obvious effects on urban land expansions. The variability on the demographic change, especially the growth of nonagricultural employees, the socioeconomic development, and the geophysical conditions, has also had effects on urban land expansion $(6,8,10,16,35,36)$. To examine the driving mechanism of urban land expansion, we regressed urban land area of 13 mega cities on some selected social and/or economic indicators, dummy variables (identifying the policy effect), and some geophysical indicators.

Because the annual data of urban land based on remotely sensed data sets, i.e. 1990-2000, are not available, it is reasonable to use construction areas of cities from the National Statistics Bureau of China $(34,37)$ as a proxy for the urban land areas together with the three phases of urban land interpreted from Landsat TM/ETM imagines in 1990, 1995, and 2000. Considering the lagged effects of the selected social and economic indicators, we replaced their current value with their 2-y lag values; that is, the 2-y lag values of nonagricultural employees to total population (NaE), 2-y lag values of Gross Domestic Product (GDP), 2-y lag values of average wages (AWs; a proxy for income level and living standard), and 2-y lag value of the foreign direct investment (FDI) in our regression model. To estimate the effects of the geophysical conditions on urban land expansion, we calculated the shares of tableland (SPlain), mean values of slope (Slope), and elevation (Elev) of the developed and underdeveloped areas of the cities.

To analyze the effects of policy changes on urban land expansion, we incorporated two dummy variables (Year1992 and Year1995) into our model. During our study period, a large number of laws, regulations, and decrees regarding land use, land protection, land acquisition, and urban land expansion were promulgated by the Congress or the State Council in China (2, $6,8,10,16,35,36)$, some of which, such as the Decree on Implementing the Land Management Law issued by the China State Council in 1991, the Regulations on Basic Farmland Protection, and the Urgent Notice on Prohibition Misuse and

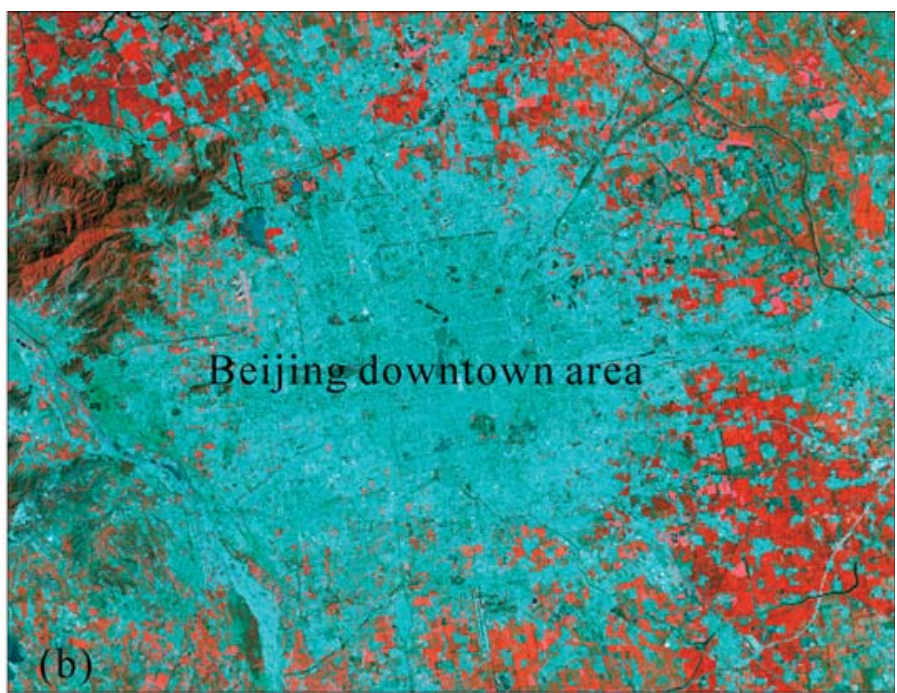

Figure 2. The urban land of Beijing expanded dramatically through concentric expansion modes identified by the Landsat TM digital image in Oct. 1984 (a) and the Landsat ETM digital images in Aug. 1999 (b). 

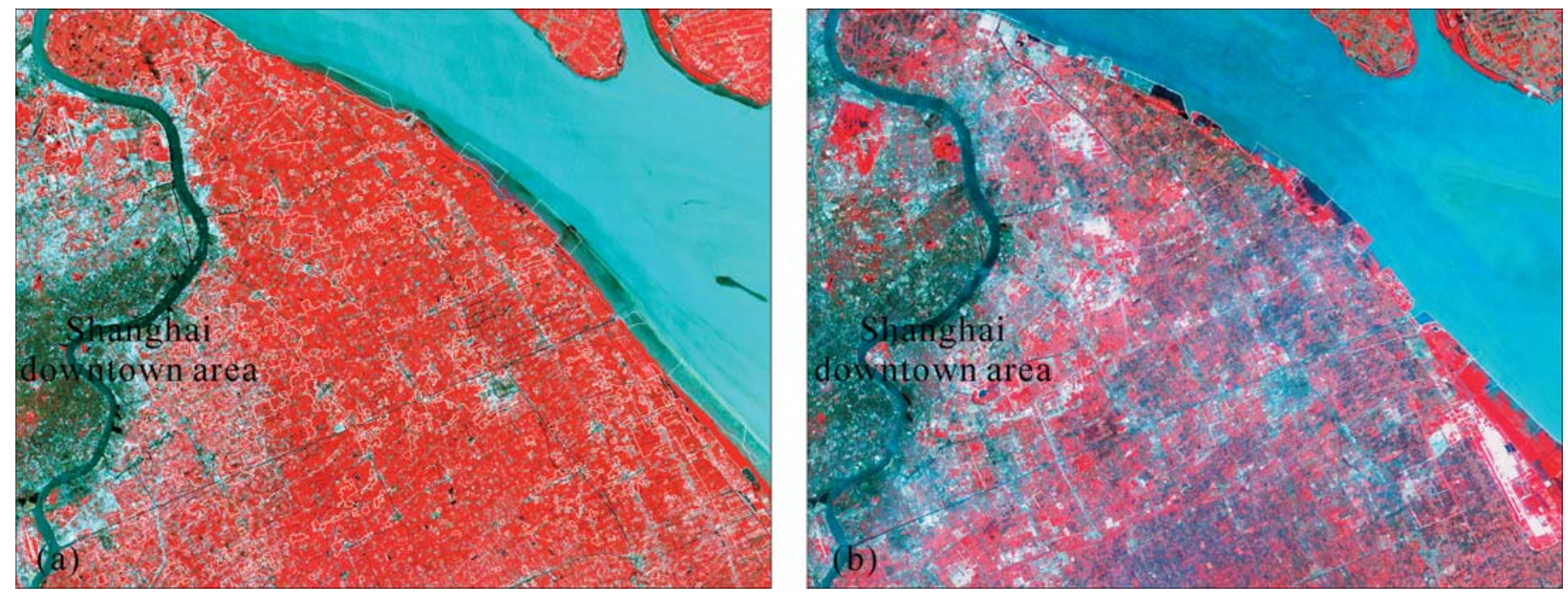

Figure 3. The identification of leapfrog modes of urban land expansion in Shanghai city by the Landsat TM images in May 1987 (a) and the Landsat ETM digital images in June 2000 (b).

Unapproved Farmland Acquisition issued by China State Council in 1992, have not been effectively implemented $(5,6,8)$. As a result, the continuous rapid urban land expansion during that period was not controlled effectively. During 1995-2000, laws such as the Decree on Basic Farmland Protection issued by the China State Council in 1994 produced negative effects on urban land expansion $(5,6,8)$.

The regression results are presented in Table 3. Demographic changes directly influence urbanization and urban land expansion $(5,6,11)$ (Table 3$)$. Table 3 shows that urban land expansion is positively related to $\mathrm{NaE}$ growth (5). The economic gap between rural and urban areas (38) and more employment opportunities in cities $(8,11)$ induced the mass population migration from rural to urban areas in China, which in turn, led to rapid increase of urban land use $(8,11)$. In addition, with the reform on the Household Registration System, a number of affluent rural surplus labors have swarmed into large cities such as Beijing and Shanghai (6). Some new social areas have emerged, including high-class suburban residential areas in some large cities, such as Beijing, Guangzhou, and Shanghai $(9,39)$.

Rapid economic growth dramatically spurs urban land expansion $(1,12,40)$. Table 3 shows that there are positive and higher coefficients between GDP and AWs with the urban land areas. In the 1990s, the average annual growth rate of GDP (calculated at 1990 constant prices) was about 12.2\% (41). With economic development, the AW was increasing simultaneously, which paved the way for the increase of living space per capita, transportation land per capita, common green belt per capita, and so on, thus directly spurring urban land expansion.

The econometric analyses also showed that FDI exercised positive effects on urban land expansion (Table 3). Especially since the acceleration of land reform in 1992, foreign investment

\begin{tabular}{|c|c|c|c|c|}
\hline $\begin{array}{l}\text { Driving } \\
\text { forces }\end{array}$ & Coefficients & $\begin{array}{l}\text { Robust } \\
\text { Standard } \\
\text { Errors }\end{array}$ & $t$ & $\boldsymbol{P}>|\boldsymbol{t}|$ \\
\hline $\mathrm{NaE}$ & 35.98 & 3.52 & 10.21 & 0.000 \\
\hline GDP & .91 & .004 & 1.54 & 0.027 \\
\hline $\mathrm{AW}$ & .84 & .269 & 3.12 & 0.002 \\
\hline FDI & .01 & .002 & 2.58 & 0.011 \\
\hline SPlain & 65.55 & 16.48 & 3.98 & 0.000 \\
\hline Elev & -1.98 & 2.31 & -0.86 & 0.394 \\
\hline Slope & 2563.02 & 425.31 & 6.03 & 0.000 \\
\hline Year 1992 & 7288.12 & 2795.57 & 2.61 & 0.010 \\
\hline Year 1995 & -1867.87 & 1901.56 & -0.98 & 0.028 \\
\hline Constant & -9450.23 & 4141.52 & -2.28 & 0.024 \\
\hline \multicolumn{5}{|c|}{$R^{2}=0.867 ; F(17,125)=91.66 ;[$ Prob $>F=0.000]$} \\
\hline \multicolumn{5}{|c|}{ Depend variable: urban land area; sample size: 143.} \\
\hline
\end{tabular}

has shown a growing interest in real estate development (9). China adopted "The Opening Door" policy in the early reform period, and as a consequence, the volume of FDI in China grew rapidly, especially in the 1990s. The opening to foreign investment has long been recognized as one of the engines of economic growth in China (40, 42, 43).

For the three selected geophysical indicators, SPline, Elev, and Slope, a higher and positive coefficient of SPlain and Slope shows that the plain lands with a lower gradient is always more favorable for urban land expansion; Elev has not passed the significant test of more than $1 \%$ (Table 3 ).

The temporal difference of the speed of urban land expansion in the first and second half of the 1990s mainly resulted from land policy change (Table 3). The two designed dummy variables passed the significance test of more than $1 \%$, with positive and negative coefficients for the first and the second $5 \mathrm{y}$, respectively, which further shows that the policy change really did have an impact on urban land expansion, and some key policies issued and implemented in the first $5 \mathrm{y}$ failed to hold back the urban land expansion, whereas those implemented in the latter $5 \mathrm{y}$ had an effect on regulating urban land expansion.

Since 1987, land reform that reintroduced land values in China through land leasing and charging of land use fees has created a property market and increased the speed of housing construction $(20,36)$. Besides the ineffectiveness of laws or regulations enforcement, there are some other managerial factors leading to the urban land expansion $(5,6,35)$; for instance, the leaders of some cities believe that urban land is more profitable than agricultural land, so they think that economic success is more likely to rely on urban land. This speeds up the rate of land conversion from cultivated land to urban land (35) and promotes urban land expansion.

Fortunately, the loss of valuable agricultural land caused by rapid urban growth has caught the attention of the central government $(5,6,8)$. Since 1994, some regulations and laws have been implemented; the implementation of the Decree on Basic Farmland Protection issued by the China State Council in 1994 prevented excess loss of cultivated land and urban land expansion. Because of the austere situation of arable land loss, the Chinese government revised the Land Management Act of China to ensure sustainable socio-economic development in 1998. The Act reclaims powers on cultivated land conversion for central government (35) and requires all construction projects that use cultivated land to submit land-use applications to the governments at the provincial level or higher for approval $(6,8$, $16,35)$. This has held back the rate of expansion of urban land to some degree. In this sense, national land use policy was one of the key factors that slowed down the land conversion during 1995-2000. 


\section{CONCLUSION}

The main findings of our analysis are simple but strong and consistent: urban lands in China expanded dramatically with obvious spatio-temporal differences. During the study period, China's urban land increased by 817 thousand hectares, of which $80.8 \%$ occurred during 1990-1995, and 19.2\% occurred during 1995-2000. It was also found that the urban lands of 13 mega cities expanded with different modes that can be ascribed to different locations, social and economic conditions, geophysical differentiation, and local policy factors. Cities located in the plains have expanded mostly in a concentric pattern, whereas cities located along coastlines, riverbanks, and valleys have primarily expanded in the linear expansion mode. It is notable that, in reality, city sprawl with only one type is very rare; most cities expand in combined modes (18).

Urban land expansion has been driven largely by demographic change, social and economic development, and the transition of land use regulation $(3,5,44)$. Three main reasons for these results were identified. First, in China, there are some enormous driving forces of mass population migration from rural to urban areas. The recent reforms on household registration systems have reduced the strict controlling on the population migration, which further promotes the population migration from rural areas to cities. Second, high economic growth (the GDP growth rate reached $11.2 \%$ ) was one of the main forces that led to urban land expansion and the increase of urban land per capita in the1990s. Third, the changes in land use policies have played the dominant role in the temporal characteristics of urban land expansion during 1990-2000.

This paper also shows that high-resolution remote sensing is effective in monitoring urban land expansion $(1,2,5,19,23,28$, $30)$. The interpretation and classification of remote sensing data can help to estimate the rate and spatial pattern of the urban growth (12). In so doing, it becomes possible to detect illegal urban land use and to enforce the urban land development regulations for reasonable and sustainable use of urban land.

\section{References and Notes}

1. Cheng, J. and Masser, I. 2003. Urban growth pattern modeling: a case study of Wuhan city, P.R. China. Landscape Urban Plann. 62, 199-217.

Ewing, R. 1994. Characteristics, cause, and the effects of sprawl: a literature review. Environ. Urban Issues. 21, 1-15.

. Fischel, W.A. 1982. The urbanization of agricultural land: a review of the National Agricultural Lands Study. Land Econ. 58, 236-259.

4. Liu, J.Y. 1996. Macro-scale Survey and Dynamic Study of Natural Resources and Environment of China by Remote Sensing. China Science and Technology Press, Beijing. (In Chinese).

5. Liu, J.Y. 2002. A study on spatial pattern of land-use change in China during 19952000. Sci. China (Series D) 32, 1031-1040.

6. Liu, S.H. 2002. Spatial Patterns and Dynamic Mechanisms of Urban Land Growth in China: Case Studies of Beijing and Shanghai, International Institute for Applied Systems China: Case Studies of Beijing and Shanghai, International Institute for Appl
Analysis (IIASA) Interim Report IR-02-005. Luxemburg, IIASA, $38 \mathrm{pp}$.

7. Ottensmann, J.R. 1977. Urban sprawl, land values and the density of development. Land Econ. 53, 389-400.

8. Tan, M., Li, X., Xie, H. and Lu, C. 2005. Urban land expansion and arable land loss in China-a case study of Beijing-Tianjin-Hebei region. Land Use Policy (In press).

. Wu, F.L. and Webster, C.J. 2001. China's recent urban development in the process of land and housing marketisation and economic globalisation. Habitat Int. 25, 273-289.

10. Zhao, X.B., Chen, Z.G. and Xue, D.A. 2002. Globalization and trend of major citie development in China. Urban Planning Overseas 5, 7-14 (In Chinese)

1. Cai, F. 1995. Determinants, trend, and the policy of population mobility in China. Chin. Demographic Sci. 6, 8-16 (In Chinese).

12. Bourne, L.S. 1996. Reurbanization, uneven urban development and the debate on new urban forms. Urban Geograph. 17, 690-713.

13. Deakin, E. 1989. Growth control: a summary review of empirical research. Urban Land $48,16-21$.

14. Herold, M., Goldstein, C.N. and Clarke, C.K. 2003. The spatiotemporal form of urban growth: measurement, analysis and modeling. Remote Sens. Environ. 86, 286-302.

5. Tania, D.M., López, T., Aide, M. and John, R.T. 2001. Urban expansion and the losses of prime agricultural lands in Putero Rico. Ambio 30, 49-54.

6. Yeh, A.G.O. and Li, X. 1996. Urban growth management in the Pearl River delta - an integrated remote sensing and GIS approach. ITC J. 1, 77-85.

17. Gordon, P. and Richardson, H.W. 1977. Are compact cities a desirable planning goal? $J$ Am. Plann. Assoc. 63, 95-106.

18. Wu, J. 1990. The Morphology of Chinese Cities: Structure, Characteristic and Growth. Jiangsu Science and Technology Publishing House, Nanjing (in Chinese).

19. Seto, K.C. and Kaufmann, R.K. 2003. Modeling the drivers of urban land use change in the Pearl River Delta, China: integrating remote sensing with socioeconomic data. Land. Econ. 79, 106-121.

20. Yeh, A.G.O. and Li, X. 1999. Economic development and agricultural land loss in the Pearl River Delta, China. Habitat Int. 23, 373-390.

21. Li, X. and Yeh, A.G.O. 2004. Analyzing spatial restructuring of land use patterns in a fast growing region using remote sensing and GIS. Landscape Urban Plann. 69, 335-354.

22. Weng, Q. 2002. Land use change analysis in the Zhujiang Delta of China using satellite remote sensing, GIS and stochastic modeling. J. Environ. Manage. 64, 273-284.
23. Ehlers, M., Jadkowski, M.A., Howard, R.R. and Brostuen, D.E. 1990. Application of SPOT data for regional growth analysis and local planning. Photogram. Engin. Remote Sen. $56,175-180$.

24. Harris, P.M. and Ventura, S.J. 1995. The integration of geographic data with remotely sensed imagery to improve classification in an urban area. Photogram. Engin. Remote Sen. 61, 993-998.

25. Meaille, R. and Wald L 1990. Using geographic information system and satellite imagery within a numerical simulation of regional urban growth. Int. J. Geogr. Info. Syst. 4, 445-456.

26. Treitz, P.M., Howard, P.J. and Gong, P. 1992. Application of satellite and GIS technologies for land-cover and land-use mapping at the rural-urban fringe: a case study. Photogram. Engin. Remote Sen. 58, 439-448.

27. Westmoreland, S. and Stow, D.A. 1992. Category identification of changed land-use polygons in an integrated image processing/geographic information system. Photogram. Engin. Remote Sen. 58, 1593-1599.

28. Yeh, A.G.O. and Li, X. 1997. An integrated remote sensing-GIS approach in the monitoring and evaluation of rapid urban growth for sustainable development in the Pearl River Delta, China. Int. Plan. Stud. 2, 193-210.

29. Deng, X., Liu, Y. and Zhao, T. 2003. Study on the land-use change and its spatial distribution: a case study in Ankang District. Resour. Environ. Yangtze Basin. 12, 522-528 (In Chinese).

30. Deng, X., Liu, J, Zhan, J and Zhao, T. 2004. Dynamic Simulation on the spatiotemporal patterns of land use change in Taips County. Geograph. Res. 23, 147-156 (In Chinese).

31. Jensen, J.R. 1996. Introductory Digital Image Processing: A Remote Sensing Perspective. (2nd edition). Prentice Hall, Upper Saddle River, p. 318

32. Turner, B.L.I., Skole, D. and Sanderson, S. 1995. Land-use and Land-cover Change. Science/Research Plan. IGBP Report; 35/IHDP Report 7, IGBP and IHDP, Stockholm and Geneva, $32 \mathrm{pp}$.

33. The Western Development Policy was inaugurated in 1999 to speed up the economic development and environmental improvement in western parts of China, which includes Xinjiang, inner Mongolia, Gansu, Ningxia, Shaanxi, Qinghai, Tibet, Sichuan, Chongqing, Guizhou, Yunnan, and Guangxi. Specifically, the policy called for increased investments in accelerating infrastructure development, with an emphasis of water resources; improving the ecological conditions with a focus on tackling desertification, soil erosion, and worsening floods; promoting industrial development; and strengthening science, technology, and education.

34. National Bureau of Statistics of China. 2001. Urban Statistical Yearbook of China. China Statistic Press, Beijing. 589 pp. (In Chinese).

35. Zhang, T. 2000. Land market forces and government's role in sprawl, the case of China. Cities 17, 123-135.

36. Ding, C. 2003. Land policy reform in China: assessment and prospects. Land Use Policy $20,109-120$.

37. National Bureau of Statistics of China 1991-2000. Urban Statistical Yearbook of China China Statistic Press, Beijing. (In Chinese).

38. Klaus, H. and Sun, L. 2001. A scenario analysis of China's land use and land cover change: incorporating biophysical information into input-output modeling. Struct. Change Econ. Dynam. 12, 367-397.

39. Wu, F.L. and Webster, C.J. 2000. Simulating artificial cities in a GIS environment: urban growth under alternative regulation regimes. Int. J. Geogr. Info. Sci. 14, 625-648.

40. Chen, J. and Warner, B.M. 1996. Regional income inequality and economic growth in China

41. National Bureau of Statistics of China. 1991-2001. China Statistical Yearbook. China Statistic Press, Beijing. (In Chinese).

42. Gao, T. 2003. The impact of foreign trade and investment reform on industry location: the case of China. J. Int. Trade Econ. Dev. 11, 367-386.

43. Demurger, S. 2001. Infrastructure development and economic growth: an explanation for regional disparities in China. J. Comp. Econ. 29, 95-117.

44. Peiser, R. 1989. Density and urban sprawl. Land Econ. 65, 193-204.

45. Acknowledgments: This study was supported by China Natural Science Foundation Grant 90202002 and National Basic Research Priorities Program, P.R. China Grant 2002CB412507. The authors thank Prof. Wang Yimou from the Cold and Arid Regions Environmental and Engineering Research Institute (CAS); Prof. Zhou Wancun from the Chengdu Institute of Mountain Hazards and Environment (CAS); Prof. Li Rendong from the Institute of Geodesy and Geophysics (CAS); Prof. Jiang Nan from the Nanjing Institute of Geography and Limnology (CAS); Prof. Zhang Shuwen from the Changchun Institute of Geography (CAS); and Prof. Wu Shixin
Institute of Ecology and Geography (CAS) for their data support.

46. First submitted 12 Jan. 2004. Revised manuscript received 14 Sept. 2004. Accepted for publication 14 Sept. 2004

Jiyuan Liu is a professor and the Director General of the Institute of Geographical Sciences and Natural Resources Research (IGSNRR), Chinese Academy of Sciences (CAS), where his research focuses on Environment Remote Sensing and GIS application. His address: IGSNRR, CAS, 11A Datun Road Anwai, Beijing, China.

liujy@igsnrr.ac.cn

Jinyan Zhan has a PhD from IGSNRR and is a research fellow at the State Key Laboratory of Resources and Environment Information System, IGSNRR, CAS. She is a modeler in the environmental sustainability and ecosystem assessment. Her address: IGSNRR, CAS, 11A Datun Road Anwai, Bejing, China.

zhanjy@igsnrr.ac.cn

Xiangzheng Deng has a PhD in cartography and GIS from IGSNRR, CAS. He is interested in detection model on land use change and land economics. His address: Center for Chinese Agricultural Policies, CAS, 11A Datun Road Anwai, Beijing, China.

dengxz.ccap@igsnrr.ac.cn 